\title{
Docência universitária e os desafios da formação pedagógica
}

\author{
University teaching and the challenges of pedagogical training
}

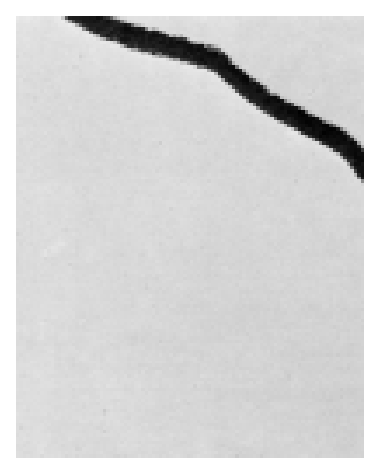

${ }^{1}$ Professora do Programa de Pós-Graduação em Educação e do Curso de Mestrado em Odontologia da Universidade Luterana do Brasil/ ULBRA. <cleofernandes@terra.com.br>

\author{
Cleoni Maria Barboza Fernandes ${ }^{1}$
}

"O conhecimento do conhecimento compromete. Compromete-nos a tomar uma atitude de permanente vigilância contra a tentação da certeza, a reconhecer que nossas certezas não são provas da verdade, como se o mundo que cada um de nós vê fosse o mundo, e não um mundo, que produzimos com outros. Compromete-nos porque, ao saber que sabemos, não podemos negar que sabemos"

Maturana e Varela

A educação concebida como prática social envolve várias dimensões e instâncias de realidades múltiplas e contraditórias, nelas situo a universidade como foco e faço um recorte que trata da docência e da formação pedagógica.

Essa expressão docência universitária-formação pedagógica é recente na vida institucional universitária. Muitos estudos têm sido realizados sobre a Universidade Brasileira, desvendando sua trajetória nas condições históricoobjetivas que explicitam as contradições e possibilidades de mudança, a organização de seus cursos, análise sobre legislações, o que tem contribuído para encaminhá-la em outras direções.

Entretanto, ainda são poucos os estudos que têm sido feitos sobre a formação pedagógica e a prática cotidiana do professor universitário - sua docência. Esse fato, de certa forma, revela o valor dado à formação pedagógica desse professor. Ao abordar esse tema, em outros estudos, constato que "no cotidiano da vida universitária, tem sido possível verificar que há preocupação institucional com a competência do profissional na área de sua formação, sem situá-la historicamente na perspectiva de ser professor" (Fernandes, 1998, p.97). 
A preocupação centra-se no espaço da educação formal, quando o professor realiza (com o aval de seu departamento) cursos de pós-graduação com ênfase na pesquisa, ficando seu desempenho como professor medido por sua produção científica (artigos, pesquisas), mas sem uma reflexão sistematizada que traga sua prática pedagógica como foco de análise.

A leitura da prática pedagógica universitária, por outro lado, mostra a continuidade de uma concepção positivista da ciência, conhecimento $e$ mundo, marcada pela certeza, pela prescrição, pela precisão, pelo conhecimento oriundo da tradição, verdade pronta, "sacramentada, solidificada, de tal maneira que não percebemos que é uma tradição" (Pessanha, 1993, p.10-1).

Essa tradição de formação do professor de ensino superior está assentada na pesquisa conforme os padrões de qualidades determinados pela pósgraduação stricto sensu. Pela análise da realidade, verificamos que os programas de doutorado e mestrado são configurados numa forma que privilegia a especialização numa ênfase ao conhecimento e numa preparação para a pesquisa.

Não se trata de negar a importância da pesquisa para o aprofundamento de seu campo científico, mas sim de situá-la em sintonia e interpenetração com outras dimensões, tão necessárias e complexas para construção de sua professoralidade - sua identidade de ser professor.

A discussão que se faz necessária antecede a preparação para a pesquisa, funda-se na tradição cultural do pensamento hegemônico ocidental que Santos (1995) denomina de paradigma dominante. Esse paradigma instaura-se com a revolução científica a partir do século XVI pelas mãos de Copérnico-Galileu-Descartes e Newton, constituindo uma ordem que admite uma única forma de conhecimento verdadeiro, denominado de conhecimento científico, uma única racionalidade, a razão cognitiva instrumental.

Galileu é a importante figura que comprova as idéias de Copérnico e afirma que a natureza pode ser conhecida pela mensuração e define o poder da razão e constitui-se como elemento de transição entre o método especulativo da Idade Média e o método experimental da Modernidade.

Descartes sistematiza a nova ordem histórica que buscava controlar a natureza e as forças do universo físico. Era necessário, naquele momento, subjugar a natureza para atender às exigências do modo de produção capitalista em expansão. Essa visão vai determinar uma nova relação da humanidade com a natureza. Uma relação mecanicista, externa que substitui a relação mediada por símbolos e mitos construídos culturalmente.

Assim, o racionalismo cartesiano independe dos objetos, estabelecendo um método único para compreendê-los. A razão em Descartes é absoluta $e$ antecede a qualquer objeto. Sua criação do método analítico consiste em desmontar fenômenos complexos em pedaços a fim de compreender o comportamento do todo a partir das propriedades de suas partes. Sua concepção de natureza está assentada em dois domínios independentes e separados: o domínio da mente e o domínio da matéria.

É a redução da riqueza da complexidade, das circularidades, que ficam

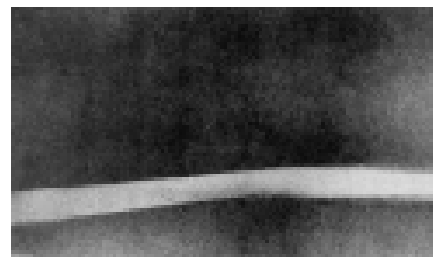


aprisionadas em modelos e proposições como verdades absolutas, em que a precisão da medição é o critério da própria verdade, sem as arquiteturas dos desejos, das emoções e das intuições, outras racionalidades que precisam compor e interagir na construção da professoralidade.

Volto a repetir, não se trata de negar as contribuições válidas para o campo científico e social, mas sim de compreender o reducionismo feito e seus desdobramentos nas concepções de conhecimento, ciência e mundo, especialmente com a relação humanidade/natureza, então separada $e$ esvaziada de sentido simbólico, mágico e existencial. Contudo, estas concepções estão entranhadas em nossas vidas e adentram conosco em nossas práticas cotidianas, sem que muitas vezes, delas tenhamos consciência.

As concepções de conhecimento que se forjam excluem os vínculos com o "mundo sensível" e com a dimensão qualitativa das relações com o conhecimento da natureza física e humana, que são substituídos por uma relação instrumental de exploração. Essa relação se configura na fragmentação do ser humano em corpo, alma e intelecto. Objetos e sujeitos estão rompidos (Pellanda, 1996). "O pensamento é uma coisa. Eu sou uma coisa que pensa. As emoções são um obstáculo ao conhecimento" (Pellanda, 1996, p.232).

Nessa lógica, o professor vem fazendo sua formação de pós-graduação, construindo uma competência técnico-científica, reconhecida e legitimada pelos seus pares e alunos; às vezes, no âmbito institucional, acredita-se estar contemplada a formação pedagógica pelo fato de, no curso de Pósgraduação, haver uma disciplina da área pedagógica.

É interessante registrar que para trabalhar na escola básica e no ensino médio, exige-se a formação pedagógica, mas o professor que atua no ensino superior "não precisa desse saber", que por sua vez, é legitimado pela Universidade na existência dos cursos de licenciatura, uma contradição que se gesta na própria concepção de conhecimento e ciência que funda seu projeto sócio-político-cultural. A ausência de conhecimentos na chamada área das ciências humanas e sociais (qual ciência não é humana, social e histórica?) que dariam conta de instrumentalizar o professor para compreender e interpretar sua docência ratifica o projeto sócio-políticocultural vigente na Universidade.

Ao discutir essa questão, também não quero reduzir a formação pedagógica à única possibilidade da formação "oficial", nem tirar o importante valor da intuição e da autoconstrução, mas essas outras possibilidades ocorrem quando há na sua gênese uma desinstalação, uma insatisfação, um desequilíbrio que rompe com a racionalidade única do paradigma dominante, em que a polarização sujeito-objeto se reconstitui na sua inteireza com incertezas, inseguranças e a busca da interpretação começa a avançar sobre o estabelecido, questionando-o em suas múltiplas, conexões, interações e imprevisibilidades (Fernandes, 1999).

A transição paradigmática que estamos vivendo, trazida pela revolução científica por meio das mãos de Planck, Einstein, Bohr e Heisenberg, encaminha outras possibilidades de múltiplas racionalidades caracterizadas por Santos (1995) como paradigma emergente, que está produzindo novas 
formas de conceber e produzir a ciência, o conhecimento e o mundo, e na qual essa transição é caracterizada como:

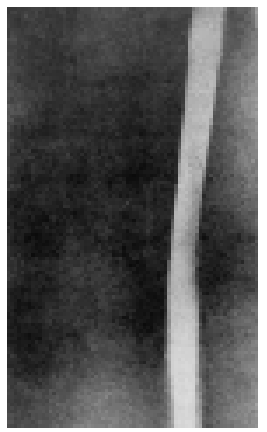

o retrato de uma família intelectual numerosa e instável, mas também criativa e fascinante, no momento de se despedir, com alguma dor, dos lugares conceituais, teóricos e epistemológicos, ancestrais e íntimos, mas não convincentes e securizantes, uma despedida em busca de uma vida melhor a caminho doutras paragens onde o otimismo seja mais fundado $e$ a racionalidade mais plural e onde, finalmente, o conhecimento volte a ser uma aventura encantada. A caracterização do paradigma dominante traz consigo o perfil do paradigma emergente.

(Santos, 2000, p.72)

Nesse outro espaço/tempo em que estamos vivendo, há a necessidade de revisitar a formação pedagógica para configurá-la como um construto teórico-prático marcado pela intencionalidade de um projeto de ação transformador e emancipatório ${ }^{2}$, que tem na sua dimensão coletiva, a possibilidade de concretude.

Esse construto teórico-prático tem como elementos fundantes os saberes da prática $e$ da teoria, entendendo a prática como uma produção de saberes, nascentes da reflexão, saboreadas - vindas realmente de sapere, saborear, etimologia latina - que devem instigar a busca de vários caminhos para o embate com a teoria, compreendida, contextualizada e recriada e não teoria posta - cadáver de conhecimento (Freire e Shor, 1987). Trata-se, então, de saberes e conhecimentos, que trazidos das chamadas ciências humanas $e$ sociais interagem com as várias epistemologias de outras áreas, tensionando as relações e tendo a possibilidade de fazer uma "humana docência, onde ser educador é ser o mestre de obras do projeto arquitetado para sermos humanos" (Arroyo, 2000, p.41).

Isto implica resgatar a eticidade humana, naquilo que nomino de ética relacional, a relação $e$ a interação com o outro em múltiplas teias de relações, conflituadas, afetivas, simbólicas, ritualísticas, em que vivemos o e no detalhe dos gestos e dos toques de nossa condição humana, por dentro do filtro cultural de produzido-produtor (Pinto, 1979) dessas mesmas múltiplas teias em suas determinações e possibilidades.

Essas determinações e possibilidades, de certa forma, têm uma corporeificação na fala de Freire (1979, p.28):

O homem não pode ser compreendido fora de suas relações com o mundo, de vez que é um 'ser em situação', um ser do trabalho e da transformação do mundo (...) Nestas relações com o mundo, através de sua ação sobre ele, o homem se encontra marcado pelos resultados de sua própria ação. Atuando, transforma, cria uma realidade que, por sua vez, envolvendo-o, condiciona sua forma de atuar. Não há portanto, como dicotomizar o homem do mundo, pois que não existe um sem o outro.
${ }^{2}$ Contextualizada nos limites impostos pelos mecanismos

reguladores de uma lógica excludente, que vem roubando a

liberdade acadêmica $e$, por desdobramento, a própria prática social, tema que não será tratado nesse trabalho, mas que necessita ser explicitado como pano de fundo na sua contingência histórica. 
${ }^{3}$ Integrando o grupo de pesquisa interinstitucional UNISINOS/ULBRA/UFPe com o projeto

"Formatos avaliativos concepções de docência universitária".
Assim, a docência universitária e a formação pedagógica, embora tenham atualmente outros contornos, pela exigência dos critérios de avaliação para fins de autorização e/ou reconhecimento, não têm sido muito atingidas, como grande parte dos estudos (pesquisas nessa área) revela, nas questões epistemológicas, políticas e pedagógicas, correndo-se o risco de reduzirmos sua existência a uma questão técnica polarizada entre conteúdo-forma; teoria-prática; ensino-pesquisa; com formação-sem formação; participaçãonão participação no Projeto Pedagógico.

Essa preocupação tem me levado a aprofundar estudos que neste momento estou realizando em parceria ${ }^{3}$, para compreender como está se dando a construção da profissionalidade do professor nessa sociedade de informações e de mecanismos reguladores e, que sem dúvida, precisamos transformar em sociedade de conhecimento na direção de um "conhecimento prudente para uma vida decente" (Santos, 1995), sem esquecer o outro sujeito dessa relação - o aluno, saberes, cultura $e$ contingências históricas, nossa condição e responsabilidade de ser professor.

Com consciência dos limites dessas reflexões e teorizações iniciais, volto ao começo, "o conhecimento do conhecimento compromete (...) compromete-nos porque, ao saber que sabemos, não podemos negar que sabemos" (Maturana e Varela, 1995, p.61) e o desafio está lançado, numa dupla responsabilidade: de a Universidade assumir um esforço intencional $e$ sistemático com a formação pedagógica de seus professores (Fernandes, 1998) e, por outro lado, talvez o mais difícil, de construir um outro Projeto para Universidade, mas esta é tarefa também de todos nós.

Sem a ingenuidade de que é tarefa fácil ou imediata, mas também comprometidos com o que sabemos, que estamos numa transição paradigmática, que nos tira "o chão" e que precisamos enfrentá-la para continuar vivendo. Vivendo sem a idéia de que somos passageiros, mas sim, nos assumindo como tripulantes dessa imensa nave planetária - TERRA superando a condição de depredadores de nós mesmos.

Utopia? Por que não?

Docência universitária e formação pedagógica: desafio de todos nós, $e$ com inúmeras questões para serem feitas. Fazer a pedagogia da pergunta (Freire e Faundez, 1998), talvez seja um primeiro passo para construção da profissionalidade deste docente universitário e sua formação pedagógica $e$ enfrentar os desafios.

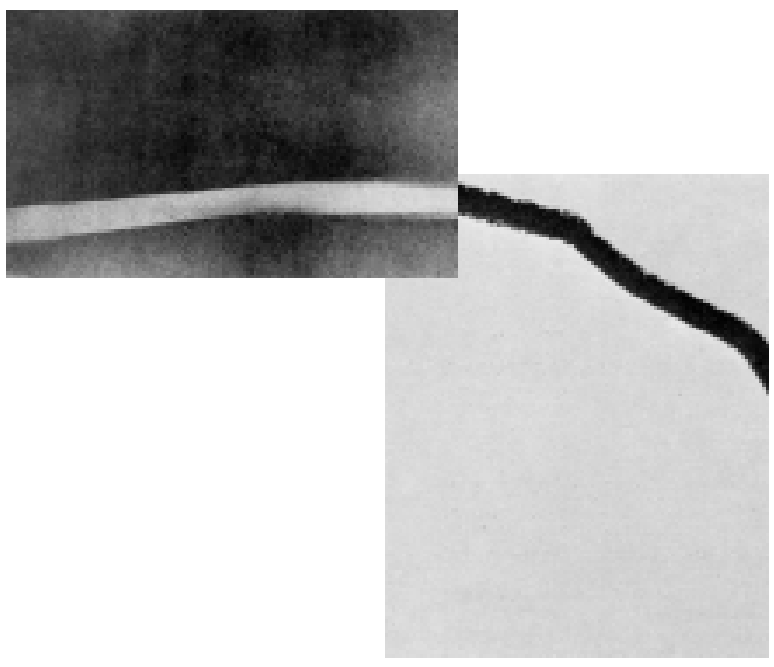

agosto, 2001 


\section{Referências bibliográficas}

ARROYO, M. Ofício de mestre: imagens e auto-imagens. Petrópolis: Vozes, 2000.

FERNANDES, C. M. B. Formação do Professor Universitário: tarefa de quem? In: MASETTO, M. (Org.)

Docência Universitária. Campinas, Papirus, 1998. p.95-112.

FERNANDES, C. M. B. Sala de aula universitária: ruptura, memória educativa, territorialidade: o desafio da construção pedagógica do conhecimento. Porto Alegre, 1999. Tese (Doutorado). Faculdade de Educação, Universidade Federal do Rio Grande do Sul, 1999.

FREIRE, P. Ação cultural para a liberdade. 4.ed. Rio de Janeiro: Paz e Terra, 1979.

FREIRE, P., FAUNDEZ, A. Por uma pedagogia da pergunta. 4.ed. Rio de Janeiro: Paz e Terra, 1998.

FREIRE, P., SHOR, I. Medo e ousadia: o cotidiano do professor. Rio de Janeiro: Paz e Terra, 1987.

MATURANA, H. R., VARELA, F. G. A árvore do conhecimento: as bases biológicas do entendimento humano. Campinas: Editorial PSY, 1995.

PELLANDA, N. M. C. Onde já se viu árvore roxa? Conhecimento e subjetividade. In: PELLANDA, N. M. C., PELLANDA, L. C. (Orgs.) Psicanálise hoje: uma revolução do olhar. Petrópolis: Vozes, 1996. p.22745.

PESSANHA, J. A. Filosofia e modernidade: racionalidade, imaginação e ética. Cad. ANPED, n.4, p.7-36, 1993.

PINTO, Á. V. Ciência e existência: problemas filosóficos da pesquisa científica. Rio de Janeiro: Paz e Terra, 1979.

SANTOS, B. Um discurso sobre as ciências. 7.ed. Porto: Afrontamento, 1995.

SANTOS, B. A crítica da razão indolente: contra o desperdício da experiência. São Paulo: Cortez, 2000.

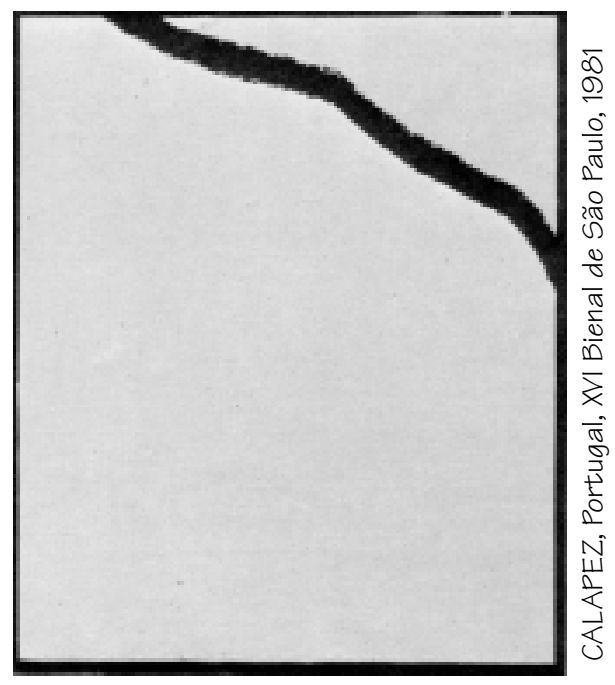

Este artigo apresenta reflexões e teorizações iniciais sobre a docência universitária e a formação pedagógica na tentativa de configurá-la como um construto teórico-prático marcado pela intencionalidade de um projeto de ação transformador e emancipatório que tem, na sua dimensão coletiva, a possibilidade de concretitude.

PALAVRAS-CHAVE: Docente; universidades; educação superior. KEY WORDS: Faculty, universities; higher education.

PALABRAS CLAVE: Docente; universidades; educación superior. 